\title{
Only Yes Means Yes: Sexual Coercion in Rural Adolescent Relationships
}

Amy J. Katz, MPH ${ }^{\text {a }}$, Devon J. Hensel, PhD ${ }^{\text {ab }}$, Abby L. Hunt, MSW ${ }^{\mathrm{c}}$, Leigh S. Zaban, M Ed ${ }^{\mathrm{c}}$,

Monique M. Hensley, AAS ${ }^{\text {c}}$, Mary A. Ott, MD MA ${ }^{a}$

${ }^{a}$ Division of Adolescent Medicine, Department of Pediatrics, Indiana University School of

Medicine, Indianapolis, IN

${ }^{\mathrm{b}}$ Department of Sociology, Indiana University Purdue University-Indianapolis, Indianapolis, IN

${ }^{\mathrm{c}}$ Health Care Education and Training, Inc., Indianapolis, IN

\section{Corresponding Author:}

Mary A. Ott, MD MA

Associate Professor of Pediatrics

Division of Adolescent Medicine

Indiana University School of Medicine

410 West $10^{\text {th }}$ Street, HS 1001

Indianapolis, IN 46202

(317) $274-8812$

(317) 274-0133 fax

maott@iu.edu

\section{Word Count: 986}

Running Head: Sexual Coercion Among Rural Adolescents

Funding: This work was supported by Health Care Education and Training, Inc. (HCET)

through the Office of Adolescent Health/DHHS Grant \#TP1AH000115 Teen Pregnancy

Prevention Program CFDA 93.297

Acknowledgements: The original abstract was previously presented as a platform session at the Pediatric Academic Societies (PAS) 2018 Meeting. 


\section{Implications and Contribution}

Consent is essential to healthy adolescent relationships, but sexual consent and coercion are under-studied in rural youth. In our study, youth from a rural high school commonly experienced sexual coercion, and female and male students identified different modifiable risk and protective factors. 


\section{ABSTRACT}

Purpose: Sexual consent is important to healthy relationships; however sexual coercion is common. We examine modifiable risk and protective factors for sexual coercion among high school students in a rural community.

Methods: We surveyed $10^{\text {th }}$ graders $(\mathrm{N}=442)$ in a rural, Midwestern, low-to-middle income county prior to receiving an evidence-based sex education program. Sexual coercion was a single item, "has anyone you were dating or going out with forced you to do sexual things that you did not want to do?". We examined associations between sexual coercion and demographics, risk behaviors, sexual self-efficacy, controlling relationship behaviors, parent communication and adverse childhood experiences (ACEs).

Results: Approximately 22\% of females and $8 \%$ of males reported experiencing sexual coercion at least once in their lifetime. Gender differences emerged in associated risk and protective factors, including: sexual sex-efficacy, controlling relationship behaviors, parent-adolescent communication about sex and ACEs.

Conclusions: Sexual coercion is common among adolescents in rural communities. Prevention interventions should target modifiable risk and protective factors. 


\section{Introduction}

Sexual consent and coercion are important adolescent health issues. Among high school students who reported dating in the past year (68.3\%), $11 \%$ of girls and $3 \%$ of boys reported being forced to do 'sexual things' they did not want to do [1]. Risk and protective factors for sexual coercion include individual factors (e.g. sexual behaviors) as well as relationship and family factors (e.g. communication and relationship quality, adverse childhood experiences [ACEs]) [2].

Gender differences exist, with females consistently reporting higher rates of experiencing sexual coercion than males. This can lead to poorer reproductive and sexual health outcomes, particularly for adolescent girls [3]. Most studies of sexual coercion focus on young adults and urban areas $[4,5]$. Data are needed for rural adolescents, as these youth frequently have little access to sexual health services and to comprehensive sex education. We examine individual, relationship, and family factors associated with sexual coercion among high school students in a rural community.

\section{Methods}

Sample. Participants in $10^{\text {th }}$ grade health classes $(\mathrm{N}=442)$ completed a paper survey before receiving an evidence-based teen pregnancy prevention program in a rural, Midwestern low-to-middle income county (September 2016 - May 2018). The Indiana University IRB and the Community Schools of Frankfort School Board approved the survey. Each participant provided informed consent. The school informed parents, invited them to review materials, and allowed parents to withdrawal their adolescent. 
Measures. The outcome variable, sexual coercion, was adapted from YRBSS [1] and asked, "In your lifetime, has anyone you were dating or going out with forced you to do sexual things that you did not want to do (Count things such as kissing, touching, or being physically forced to have sexual intercourse)?"' We dichotomized to never vs. ever. Predictor variables were drawn from the socioecological model. Individual factors included: age, self-identified gender, race/ethnicity, ever had sex (yes/no), prior alcohol and/or marijuana use (yes/no) and sexual self-efficacy (6 Likert-type items, $\alpha=0.65$; e.g. "I can say no to sex"[6]). Relationship and family factors included: controlling relationship behaviors ( 4 yes/no items, $\alpha=0.74$; e.g. "have you had a girlfriend, boyfriend, or sexual partner try to control where you go, who you see, or what you do?"[7]), parent communication (2-items ranging from not at all true-very true: "I feel comfortable talking to my parent or guardian about sex" and "If I asked about sex, my parent or guardian would get mad or angry"[8]), and ACEs ( 8 yes/no items, $\alpha=0.73$; e.g. "have you ever lived with a parent or guardian that got divorced?"[9]).

Statistical Procedure. We assessed bivariate associations between risk and protective factors and coercion. We tested for and found interactions with gender; thus, females and males were analyzed separately. Significant predictors were entered into a multivariate logistic regression model (SPSS 25.0), using a stepwise approach to eliminate nonsignificant variables.

\section{Results}

Participants had a mean age of 15.6 years, half were female and half Latino (Table 1). Thirty percent reported ever having sex, $65 \%$ reported alcohol use and $27 \%$ marijuana use. Sexual self-efficacy was at the upper end of the range, and over a quarter experienced controlling relationship behaviors. We observed a range of reported comfort talking to parents about sex and expectations that parents were willing to talk about sex. Average number of ACEs was 1.9 
$(\mathrm{SD}=2.0)$. Sexual coercion was reported by $15 \%$ of participants, $22 \%$ of females and $8 \%$ of males.

Among females ( $N=217$, Table 2), experiencing sexual coercion was associated with experiencing controlling relationship behaviors ( $\mathrm{OR}=3.10,95 \% \mathrm{CI}=1.48-6.49)$, discomfort talking to parents about sex, and more ACEs (OR=1.36, 95\% CI=1.16-1.61). Compared to girls who were very comfortable talking to a parent about sex, those who were 'not at all' had almost 3 times the odds of experiencing coercion $(\mathrm{OR}=2.86,95 \% \mathrm{CI}=1.06-7.71)$, while those who felt unsure or only a little comfortable had about 1.5 times the odds.

Among males ( $\mathrm{N}=215$, Table 2), experiencing sexual coercion was associated with lower sexual self-efficacy $(\mathrm{OR}=0.73,95 \% \mathrm{CI}=0.58-0.91)$, experiencing controlling relationship behaviors ( $\mathrm{OR}=4.32,95 \% \mathrm{CI}=1.24-15.09)$, and lower expectations that parents will be willing to talk about sex. Compared to boys who had higher expectations that parents would be willing to talk about sex, those who were undecided had over 5 times the odds ( $\mathrm{OR}=5.49,95 \% \mathrm{CI}=1.23$ 24.62) of experiencing coercion.

\section{Discussion}

Sexual coercion is common for $10^{\text {th }}$ graders in a rural high school, with girls experiencing higher rates than boys. The rates reported in our study were twice as high as a nationally representative sample (Females: $22 \%$ vs. $11 \%$ nationally; Males: $8 \%$ vs. $3 \%$ nationally) [1]. This is likely due to a variety of influences - youth in rural communities have less access to sexual health services and medically accurate, comprehensive sex education, and may hold more traditional gender roles with higher acceptance of interpersonal violence within relationships. 
Difficulties with parent-adolescent communication about sex were associated with sexual coercion for both females and males. It is unclear which direction these effects work. Although parent-adolescent communication difficulties might put youth at risk for coercion, youth who experience coercion may also be less willing to talk to their parents, as coercion can be a shaming experience.

Gender role expectations appear to be important. Interpersonal violence and not involving parents in discussions about sex are consistent with more traditional expectations of masculinity [10]. Our findings of higher reported experiences of coercion among boys with lower selfefficacy may also align with more traditional views of masculinity, which emphasize male control and self-mastery.

Although we only report on one community, and used a cross-sectional design, our study provides initial insight into the experience of sexual coercion for rural youth. Interventions that facilitate parent-adolescent communication should address adolescents' comfort with the conversation and their perceptions about parental openness to a sexual health discussion [8]. Consistent with literature demonstrating gender differences in effectiveness of dating violence interventions [2], our findings reinforce the importance of sex education programs for rural youth, addressing traditional expectations around gender (masculinity and femininity) and their roles in healthy relationships. 


\section{References}

1. Center for Disease Control and Prevention. [2017] Youth Risk Behavior Survey Data. Available at: https:/www.cdc.gov/healthyyouth/data/yrbs/pdf/2017/ss6708.pdf. Accessed on July 1, 2018.

2. Tharp AT, DeGue S, Valle LA, et al. A Systematic Qualitative Review of Risk and Protective Factors for Sexual Violence Perpetration. Trauma, Violence, \& Abuse 2013;14:133-167. DOI: 10.1177/1524838012470031.

3. Lee RLT, Loke AY, Hung TTM, Sobel H. A systematic review on identifying risk factors associated with early sexual debut and coerced sex among adolescents and young people in communities. J Clin Nurs 2018; 27:478-501. DOI: 10.1111/jocn.13933.

4. Pugh B, Becker P. Exploring Definitions and Prevalence of Verbal Sexual Coercion and Its Relationship to Consent to Unwanted Sex: Implications for Affirmative Consent Standards on College Campuses. Behavioral sciences (Basel, Switzerland) 2018;8:69. DOI: 10.3390/bs8080069.

5. Niolon PH, Vivolo-Kantor AM, Latzman NE, et al. Prevalence of teen dating violence and co-occurring risk factors among middle school youth in high-risk urban communities. J Adolesc Health 2015; 56:S5-13. DOI: 10.1016/j.jadohealth.2014.07.019.

6. Rostosky SS, Dekhtyar O, Cupp PK, Anderman EM. Sexual Self-Concept and Sexual Self-Efficacy in Adolescents: A Possible Clue to Promoting Sexual Health? The Journal of Sex Research 2008;45:277-286. https://doi.org/10.1080/00224490802204480.

7. Casey EA, Querna K, Masters NT, et al. Patterns of Intimate Partner Violence and Sexual Risk Behavior among Young Heterosexually Active Men. Journal of sex research 2016;53:239-250. DOI: 10.1080/00224499.2014.1002125.

8. Edwards LL, Hunt A, Cope-Barnes D, et al. Parent-Child Sexual Communication Among Middle School Youth. The Journal of Pediatrics 2018;199:260-262. DOI: 10.1016/j.jpeds.2018.02.041.

9. Sacks V, Murphey D, Moore K. Research brief: Adverse Childhood Experiences: National and State-Level Prevalence. Child Trends 2014. Available at: https://www.childtrends.org/wp-content/uploads/2014/07/Brief-adverse-childhoodexperiences_FINAL.pdf. Accessed July 1, 2018.

10. Bell DL, Rosenberger JG, Ott MA. Masculinity in adolescent males' early romantic and sexual heterosexual relationships. American journal of men's health 2015;9:201208. DOI: $10.1177 / 1557988314535623$. 


\section{Table 1}

Individual, Relationship and Family Characteristics and Experiences of Sexual Coercion by Gender

\section{Individual}

Age (range, 13-19)

Race/ethnicity

White

Latino

Native American

African American or Black

$>1$ race, other

Ever had sex

Prior alcohol use

Prior marijuana use

Sexual self-efficacy (range, 7-24)

Relationship

Experienced controlling relationship behaviors

Family

Comfort talking to a parent about sex

Very true

Not sure

A little true

Not at all true

Expectation that parent will be willing to talk about sex

Very true

Not sure

A little true

Not at all true

Adverse childhood experiences (range, 0-8)

\section{Outcome}

Experienced Sexual Coercion

$\mathrm{M}=$ Mean, $\mathrm{SD}=$ Standard Deviation;

$\begin{array}{cc}\text { Female } & \text { Male } \\ \mathrm{N}(\%) \text { or M }[\mathrm{SD}] & \mathrm{N}(\%) \text { or M [SD] }\end{array}$

$\begin{array}{cc}15.5[0.6] & 15.7[0.7] \\ 96(44 \%) & 84(39 \%) \\ 106(49 \%) & 117(55 \%) \\ 3(1.4 \%) & 3(1.4 \%) \\ 1(0.5 \%) & 2(0.9 \%) \\ 11(5.1 \%) & 7(3.3 \%) \\ 64(30 \%) & 61(29 \%) \\ 149(70 \%) & 127(59 \%) \\ 55(26 \%) & 62(29 \%) \\ 20.6[2.4] & 19.8[2.6]\end{array}$

$59(28 \%) \quad 47(22 \%)$

$\begin{array}{ll}67(31 \%) & 59(28 \%) \\ 15(6.9 \%) & 18(8.6 \%) \\ 85(39 \%) & 87(42 \%) \\ 49(23 \%) & 45(22 \%)\end{array}$

$17(7.9 \%) \quad 15(7.2 \%)$

$31(14 \%) \quad 26(12 \%)$

$39(18 \%) \quad 50(24 \%)$

$129(60 \%) \quad 118(57 \%)$

$2.2[2.1] \quad 1.6[1.7]$

$46(22 \%) \quad 16(7.5 \%)$ 


\section{Table 2}

Predictors of Sexual Coercion by Gender among Rural High School Students - Multivariate Logistic Regression

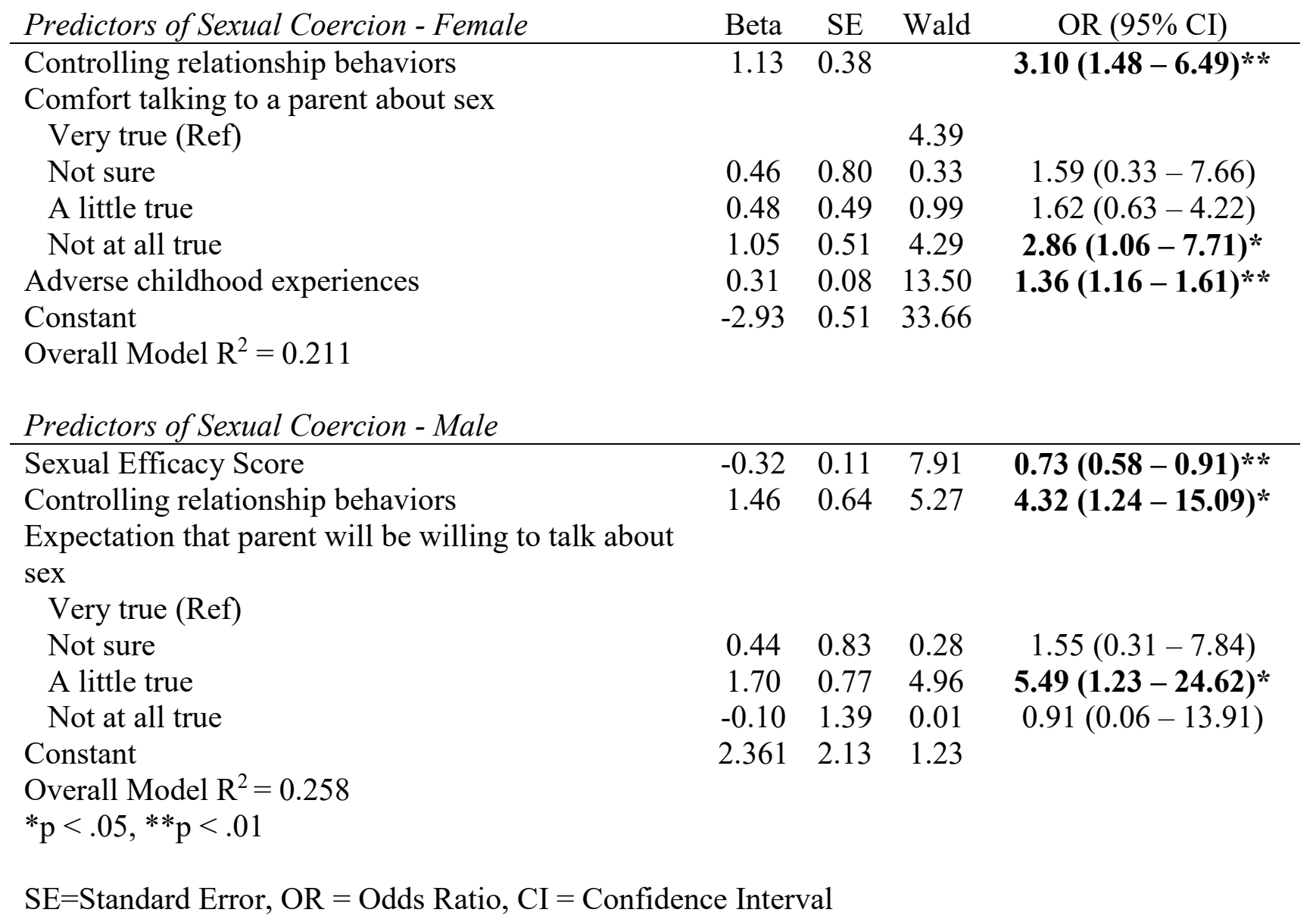

